\title{
O COTIDIANO ESCOLAR E A FORMAÇÃO CONTINUADA DOCENTE EM CONTEXTO: RELATO DE EXPERIÊNCIA
}

\author{
EL COTIDIANO ESCOLAR Y LA FORMACIÓN CONTINUADA DOCENTE EN \\ CONTEXTO: RELATO DE EXPERIENCIA
}

\section{DAILY SCHOOL ROUTINE AND CONTINUING TEACHER EDUCATION IN CONTEXT: EXPERIENCE REPORT}

Ivan FORTUNATO ${ }^{1}$

\begin{abstract}
RESUMO: Este artigo relata uma experiência de formação continuada desenvolvida com professores de uma escola estadual, da diretoria regional de Itapetininga, durante uma Aula de Trabalho Pedagógico Coletivo (ATPC). Trata-se da descrição e análise de uma atividade formativa, voltada para percepção do próprio cotidiano escolar vivido, com o propósito de promover a reflexão constante, necessária para o desenvolvimento da docência. $\mathrm{O}$ objetivo principal do artigo é demonstrar, por meio de um exemplo, como pode ser a prática de um processo de formação continuada pela parceria, mas, principalmente, colocar em evidências questões fundamentais da própria formação continuada, que jamais se encerra em uma única atividade. Ao final, espera-se que a experiência relatada sirva somente como um balizador inicial para o agenciamento constante de atividades formativas nas escolas.
\end{abstract}

PALAVRAS-CHAVE: Formação continuada. Formação de professores. Relato de experiência.

RESUMEN: Este artículo relata una experiencia de formación continuada desarrollada con profesores de una escuela estatal, de la dirección regional de Itapetininga, durante una Aula de Trabajo Pedagógico Colectivo (ATPC). Se trata de la descripción y análisis de una actividad formativa, orientada a la percepción del propio cotidiano escolar vivido, con el propósito de promover la reflexión constante, necesaria para el desarrollo de la docencia. El objetivo principal del artículo es demostrar, por medio de un ejemplo, cómo puede ser la práctica de un proceso de formación continuada por la asociación, pero, principalmente, poner en evidencias cuestiones fundamentales de la propia formación continuada, que jamás se encierra en una única actividad. Al final, se espera que la experiencia relatada sirva solamente como un balizador inicial para el agenciamiento constante de actividades formativas en las escuelas.

PALABRAS CLAVE: Formación continua. Formación de professores. Relato de experiencia.

ABSTRACT: This paper reports an experience of continuous formation developed with teachers of a state school, from the regional board of Itapetininga, during an Hour of Collective Pedagogical Work (ATPC, in Portuguese). It is the description and analysis of a formative

${ }^{1}$ Instituto Federal de São Paulo (IFSP), Itapetininga - SP - Brasil. Docente na Coordenadoria de Formação Pedagógica. Doutorado em Desenvolvimento Humano e Tecnologias (UNESP). ORCID: https://orcid.org/00000002-1870-7528. E-mail: ivanfrt@yahoo.com.br

RPGE- Revista on line de Política e Gestão Educacional, Araraquara, v. 24, n. 3, p. 1666-1678, set./dez. 2020. e-ISSN:1519-9029 
activity, focused on the perception of the daily school life experienced, with the purpose of promoting constant reflection, necessary for the development of teaching. The main objective of the article is to demonstrate, by means of an example, how the practice of a process of continuous formation by the partnership can be, but, mainly, to put in evidence fundamental questions of the own continued formation, that can never be reduced to a single activity. In the end, it is hoped that the reported experience will serve only as an initial marker for the constant assumption of training activities in schools.

KEYWORDS: Teacher education. Permanent education. Experience report.

\section{Introdução}

Não podemos separar a formação do contexto de trabalho, porque nos enganaríamos em nosso discurso. Ou seja, tudo o que se explica não serve para todos nem se aplica em todos os lugares. O contexto condicionará as práticas formadoras, bem como sua repercussão nos professores, e, sem dúvida, na inovação e na mudança (IMBERNÓN, 2009, p. 9).

Este artigo tem como objetivo descrever e analisar o resultado de uma experiência formativa realizada em uma escola estadual, da região de Itapetininga, no sudoeste paulista, durante um período semanal destinado à formação continuada e constante capacitação docente nomeado de Aula de Trabalho Pedagógico Coletivo - a ATPC. Metodologicamente, portanto, trata-se de um relato de experiência o qual tem se trabalhado sistematicamente como instrumento de e para pesquisa educacional, composto por diversos elementos, incluindo: antecedentes para a ação, o local, o motivo, o(s) agente(s), os envolvidos, uma epistemologia para ação, o planejamento, a execução e uma análise por uma lente teórica (FORTUNATO, 2018a).

Para desenvolver este relato, o artigo foi organizado em quatro sessões. Na primeira, buscou-se contextualizar a experiência, incluindo os cinco primeiros elementos, a saber: (1) antecedente, (2) local, (3) motivo, (4) agente e (5) envolvidos. Na seção seguinte, a (6) epistemologia para a ação foi tratada exclusivamente, pois se trata de refletir de forma mais aprofundada a respeito da formação continuada, particularmente em contexto, conforme ideado na epígrafe. A terceira seção trata de descrever o (7) plano e (8) ação realizada na ATPC, pormenorizando a estratégia pensada, seu desenvolvimento e os desdobramentos. Por fim, coloca-se uma (9) lente teórica, também ancorada na formação em contexto, com o objetivo de compreender a ação, bem como identificar limitações e possibilidades para ações futuras.

Ao final, espera-se que a partilha deste relato de experiência seja tomado apenas como essencialmente é: uma experiência, realizada em um momento, com um coletivo docente, para tratar do cotidiano de uma escola. Por isso, não se configura como uma proposta invariável, que 
deve ser replicada amiúde. Ainda assim, fica a esperança de que sirva como subsídio para constante reflexão sobre formação continuada de professores em exercício.

\section{Apresentação e contexto}

No caso dessa experiência, aponta-se como antecedente o desenvolvimento de um curso de extensão, nomeado "Saberes Pedagógicos: perspectivas e tendências", o qual foi ofertado em 2018, via parceria entre o Instituto Federal de São Paulo e a Diretoria de Ensino, para cerca de 40 participantes, sendo o público alvo supervisores(as), diretores(as) e coordenadores(as) de escolas da educação básica. O curso foi trabalhado numa perspectiva de pesquisa-ação, no qual os participantes foram estimulados a refletir sobre algumas considerações fundamentais a respeito da profissão docente, relacionando-as diretamente às particularidades de seu cotidiano escolar vivido. Durante o curso, pode-se refletir sobre a realidade concreta de cada unidade escolar, além de partilhar saberes e experiências positivas, com o objetivo colaborativo - mais a respeito do desenvolvimento do curso pode ser lido em outro relato de experiência (FORTUNATO, 2018b). Assim, uma das participantes do curso, diretora de escola, gostou da abordagem e entendeu que seria interessante estender parte do trabalho formativo a todos os docentes da escola sob sua gestão. Veio, então, o convite para que comparecesse a uma das regulares ATPC, com o propósito de partilhar, com o coletivo de professores, um pouco a respeito do tema central do referido curso de extensão.

O local da ação tornou-se essa escola estadual, da Diretoria de Ensino da região de Itapetininga. Há algumas particularidades muito notórias nessa escola, como, por exemplo, sua localização: fica num bairro de transição entre a cidade e sua zona rural, tendo como boa parte do alunado meninos e meninas que moram em fazendas e sítios muito distantes das salas de aula; alguns, relata a direção, viajam cerca de 40 quilômetros diários entre a casa e a escola. Outra característica que a torna distinta é seu tamanho: apenas três salas de aula, totalizando exclusivamente seis turmas distintas, do sétimo ano do ensino fundamental ao terceiro do ensino médio, sem aulas noturnas. Isso impacta, obviamente, na quantidade de docentes, contando apenas com 13 professores, todos efetivos.

Já o motivo, embora tenha sido mencionado anteriormente que a direção tenha demonstrado interesse pela atualização vivida no curso de extensão em outra oportunidade, antes da efetiva realização atividade formativa, apresentou dois novos argumentos para esse trabalho. O primeiro estava relacionado com a motivação do corpo docente que, sempre comprometido com a escola e seus estudantes, somente se beneficiaria com a possibilidade de 
dialogar mais sobre a própria profíssão. Segundo, e mais importante, era a necessidade de manter a coesão no grupo, pois estavam enfrentando dificuldades de indisciplina e pequenos atos de vandalismo com uma turma específica de adolescentes, o que não era comum naquela escola. Nada grave, relatou-se. Contudo, as dificuldades no controle disciplinar dessa sala, alguns estragos nas cortinas e cadeiras eram coisas que estavam incomodando boa parcela do corpo docente, carecendo um olhar mais atento para manutenção de um coletivo coeso e cooperativo, resultado de anos de investimento na gestão da equipe.

Tendo estabelecido o local e o motivo da experiência, pode-se apresentar os elementos humanos da ação, sendo os agentes e os envolvidos. Tornei-me agente deste trabalho formativo por causa da experiência anterior, na ocasião do curso de extensão ofertado em parceria com a Diretoria de Ensino. Possuo algumas credenciais que me habilitaram para essa tarefa de atuar na formação continuada, pois sou professor de licenciatura há mais de dez anos, coordenador de curso de graduação de formação de professores, e docente credenciado no Programa de PósGraduação em Educação, da Universidade Federal de São Carlos, campus Sorocaba, na linha de Formação de Professores e Práticas Educativas. Mesmo assim, tenho buscado colocar a vontade de aprender e a constante reflexão sobre os desafios cotidianos da docência como elementos muito mais significativos que os próprios descritores que, na aparência, dão credibilidade ao que se fala a respeito da profissionalização e o exercício da docência.

Já os envolvidos, conforme delineado anteriormente, fazem parte do corpo docente efetivo da escola que, semanalmente, se encontram durante a ATPC para discutir assuntos relacionados à escola, às salas de aula, as novidades em termos de regimentos e decretos, enfim, temas da profissão. Sua experiência docente variava bastante, como em todo coletivo de professores, tendo professores com três anos de experiência e outros com mais de 15. O grupo é bastante integrado, trabalhando na escola sob mesma direção há mais de um lustro, tendo tempo suficiente para se conhecer e estabelecer laços fraternos, indo além do convívio de oficio. Tal descrição serviu de base para pensar a forma de trabalho coletiva, pois não se tratava de uma ação para fortalecimento de equipe, mas, de um convite à reflexão a respeito das contingências do cotidiano que estariam interferindo, positiva e/ou negativamente, na ação docente.

\section{Da epistemologia da formação continuada em contexto}

Os últimos 30 anos do século XX nos deixaram como herança significativos avanços na formação continuada: a crítica rigorosa à racionalidade técnico- 
formadora; uma análise dos modelos de formação; a crítica à organização dos responsáveis pela formação; a potencialização da formação de assessores do processo; a análise das modalidades que implicam uma maior ou menor mudança; a formação próxima às instituições educacionais; os processos de pesquisa-ação como procedimento de desafio e crítica e de ação- reflexão para a mudança educacional e social, com um professor- pesquisador teórico; um maior conhecimento da prática reflexiva, dos planos de formação institucionais, além de uma maior teorização sobre a questão. Trata-se de conceitos que ainda aparecem principalmente em papéis (e, com certeza, alguns deixo de mencionar), e, embora passem longe de muitos pontos da prática formadora, permanecem na letra impressa (IMBERNÓN, 2010, p. 8).

Com a epígrafe busca-se ressaltar o que se pode nomear como paradoxo da formação de professores: a produção da teoria e a realidade concreta dos lugares da educação ainda parecem desconhecidas entre si. Pois, como afirmou o autor, há enorme desenvolvimento "no papel”, porém estagnação na "prática formadora". De certa forma, não posso deixar de concordar com o exposto, tendo como evidências minha própria escolarização (o que é limitado e arbitrário), mas também leituras diversas, incluindo o figadal "Cuidado, Escola!" (HARPER et al., 1987), além do convívio direto como formador com instituições educacionais, durante praticamente uma década. Por isso, tenho buscado articular práticas como a que se descreve neste relato, pois, embora insuficientes para eliminar as discrepâncias entre o pensado e o executado, elas tendem a apequenar o paradoxo da formação. Trata-se da formação em contexto, conforme foi preconizada por Imbernón (2010) na epígrafe.

Inforsato e Passalacqua (2018) elaboraram um estudo de revisão de teses e dissertações nacionais que corroboram com as ideias da evolução na formação docente arroladas na epígrafe e com a proposta de formação em contexto. Segundo os autores houve crescente preocupação com a formação inicial e continuada de professores no país, como reflexo das políticas educacionais promovidas a partir da Lei de Diretrizes e Bases da Educação Nacional, a Lei no. 9394/96. Já na década de 1990, algo em torno de 15\% da produção da pós-graduação nacional inventariada pelos autores estava voltada para a formação continuada em serviço (ora referida como "em exercício"), sendo que, nessa época, a racionalidade técnica estava começando a ser superada pela formação reflexiva e pesquisas mais imersas no campo da atuação docente.

Ao longo do seu levantamento sistemático, Inforsato e Passalacqua (2018) encontraram um consenso entre os autores das teses e dissertações de que a teoria deve ser elaborada com vistas à prática reflexiva, cooperativa e que valorize tanto os saberes quanto à experiência docente, sendo que, ressaltam, "as ações de formação continuada devem ser realizadas dentro do espaço escolar, no exercício da função docente e fundamentadas nas necessidades dos professores" (p. 44). Sem esse contexto, o que se tem são práticas formativas alegóricas e/ou 
vagas e/ou aleatórias e/ou autoritárias, incapazes de mobilizar a renovação constante e necessária da ação docente. Pior, como atesta Menezes (2003), desrespeitando os saberes e a experiência dos professores que se pretende capacitar.

Nessa mesma direção, explica Gatti (2003, p. 192) que "programas que visam a mudanças cognitivas, de práticas, de posturas, mostram-se ineficazes. Sua centralização apenas nos aspectos cognitivos individuais esbarra nas representações sociais e na cultura de grupos". Com isso a autora quer chamar a atenção para a formação fora de contexto, ou seja, aquela que se pretende ensinar algo de forma generalizada a um grupo de professores, sem considerar, mínimo que seja, a realidade em que atuam.

Dessa maneira, evidencia-se que para propor ações voltadas formação continuada em exercício é preciso compreender o contexto. Isso tem sido feito por meio de perguntas que ajudam a esquadrinhar as circunstâncias de cada local: quem são os docentes? Onde estão? Com quem atuam cotidianamente? Que dificuldades coletivas enfrentam no momento? O que importa aprender com essa ação educativa, ou melhor, para onde devem direcionar o foco da ação? Dessa forma, entende-se a formação continuada da mesma forma que Menezes (2003, p. 313), isto é, articulando o "compromisso dos educadores com a mudança e com a construção contínua de sua educação, buscando dar significado à teoria vinculada à prática”.

Com isso, torna-se possível apresentar uma súmula do que se compreende como formação continuada em contexto, a qual tem balizado experiências como a que aqui se descreve e analisa. Primeiro, as ações se desenvolvem no próprio ambiente escolar, pois é sobre esse local que se deve refletir de forma mais ampla e específica. Segundo, a teoria que se trabalha deve ser escolhida a partir dos temas gerados no, pelo e para o próprio cotidiano; isso não significa atuar na solução estrita de um problema, tampouco promover ações formativas somente quando se depara com uma situação adversa, pois sua essência não deve ser a solução de problemas, mas, antes, a constante reflexão ocasionada por uma postura crítica e investigativa. Terceiro, há que se considerar, sempre, os saberes docentes individuais e coletivos já construídos pela formação anterior e pela experiência, evidenciando-os pela partilha na ação dialogada, colaborando para que o grupo formule hipóteses e viabilize métodos que possam ser desenvolvidos pelo próprio grupo. Isso porque o agente da formação sai de contexto no final do processo, enquanto os docentes por lá permanecem, diariamente, com a responsabilidade de educar.

Obviamente que tal súmula não dá conta de recobrir toda complexidade da formação docente em contexto. Torna-se apenas uma fórmula suficiente para promoção da ação. Não está pronta e acaba. Pelo contrário, configura-se metaforicamente como um ponto de parada no 
contínuo existencial da formação, o qual fornecerá novos elementos para novas reflexões a respeito da docência.

\section{Da experiência concreta: do plano à ação}

Na formação, múltiplos fatores influenciam, como, por exemplo, a cultura e a complexidade das instituições de ensino, a comunicação entre os professores, a formação inicial recebida, a complexidade das interações da realidade, os estilos de liderança escolar, as relações e a compreensão por parte da comunidade escolar, as relações e os sistemas de apoio da comunidade profissional, etc. Nesse cenário complexo, as situações problemáticas que aparecem não são somente instrumentais, já que obrigam o educador a elaborar e a construir o sentido de cada situação [...] A profissão docente sempre foi complexa por ser um fenômeno social, já que numa instituição educativa e numa sala de aula devem ser tomadas decisões rápidas para responder às partes ao todo, à simplicidade ou à linearidade aparente do que há à frente e da complexidade do entorno que preocupa (IMBERNÓN, 2010, p. 100).

Com a citação apresentada na epígrafe, reforçamos a complexidade que envolve tratar da formação de professores, afinal, são múltiplos, confluentes e/ou congruentes elementos que interferem e modificam a prática docente cotidiana que, inclusive, pode ser considerada situacional. Assim, somente de posse das informações apresentadas na contextualização dessa experiência - na qual se delineou o antecedente para que a ação fosse promovida, descreveu-se a escola como local, identificou-se os motivos geradores e o coletivo docente envolvido partiu-se para o planejamento do que seria realizado durante o tempo disponível para o trabalho formativo: uma ATPC que, nessa escola, tem duração semanal de duas horas/aula, ou seja, uma hora e quarenta minutos. Nesse tempo, era preciso dar conta, portanto, de duas coisas fundamentais: chamar atenção para a situação-problema vivida com indisciplina e algumas avarias ao patrimônio, mas, principalmente, evidenciar a harmonia coletiva que havia sido estabelecida ao longo dos anos de convivência na escola.

Necessário registrar que partes fundamentais para o bom desenvolvimento da atividade foram previamente realizadas pela direção da escola: sinalizar ao corpo docente a agenda de trabalho, com a participação de um agente externo ao coletivo, que atua diretamente com a formação docente, além de fornecer os dados já demarcados como antecedentes, permitindo que se elaborasse uma proposta em contexto. Dessa forma, projetou-se para a ATPC uma atividade dinâmica a ser realizada em três etapas, nomeadas da seguinte maneira: (1) reflexão individual, (2) construção coletiva e (3) partilha. 
Assim, na data e hora acertadas, nos encontramos na sala onde habitualmente acontece a ATPC, que é uma das três salas de aula da escola. O local estava organizado como um semicírculo, que é a disposição habitualmente utilizada nos momentos coletivos da ATPC, revelando excelente prática regular desses momentos de trabalho pedagógico semanal. No caso da nossa experiência, após as boas-vindas dadas pela diretora e da formal apresentação de quem conduziria a atividade naquela noite, já partimos para o trabalho planejado, começando pela etapa I, a reflexão individual.

Apesar de toda preparação anterior, foi necessário iniciar a ATPC com alguns balizadores para o trabalho, recuperando rapidamente a atuação direta na formação inicial de professores como docente de licenciatura há alguns anos, o papel na coordenação de curso e de orientador de mestrados específicos na linha de formação de professores. Reforcei o curso de extensão realizado na Diretoria de Ensino, durante o qual discutimos sobre a atualização das ideias a respeito de "saberes pedagógicos". Por fim, expliquei que havia um propósito maior para aquela atividade, que seria deixar alguns elementos para que ela fosse além dela mesma, ou seja, que nosso trabalho daquela ATPC não fosse considerado terminado naquele dia, mas, que de certa forma começasse naquele encontro. Para isso, foi dito que era necessário encarar a atividade dessa maneira, deixando-a ecoar posteriormente no exercício da profissão.

Assim, foi entregue, para cada um dos professores presentes, um papel cartão na cor vermelha acompanhada da seguinte divisa: “individualmente, invista um tempo, algo próximo de cinco minutos, para registrar, nesse cartão vermelho, elementos negativos/problemáticos/indesejados da docência, evidenciados no cotidiano da escola". Foi reforçado que essa etapa era individual, no qual cada um anotaria, por meio de palavras-chave, o que considerava aspectos insatisfatórios da profissão. Eis, então, que outro cartão, de cor verde, foi entregue com uma divisa muito semelhante: anotar palavras-chave que representassem um pensamento, mas, dessa vez, a respeito de aspectos positivos/triunfantes/desejadas do cotidiano docente... Eis que deixo aqui uma nota a respeito dessa primeira etapa, para que possa refletir mais profundamente a respeito em outro momento: cinco minutos parece ser muito tempo para que se anote a parte ruim da coisa, como se o foco estivesse sempre direcionada para o cartão vermelho, pois, nos mesmos cinco minutos, a maioria dos cartões verdes permanecia praticamente intacta, com um ou dois registros apenas.

Depois de concluída a primeira etapa, passamos para a seguinte, a da construção coletiva. Reunidos em três pequenos grupos, foi lhes solicitado que lessem suas palavras-chave registradas nos dois cartões, explicando a escolha de cada uma, definindo situações que evidenciassem cada aspecto negativo ou positivo. No primeiro momento, enquanto um contava 
a respeito de suas palavras-chave, os demais deveriam apenas ouvir, sem interferência (nota: fazer isso efetivamente é muito difícil). Depois, foi lhes solicitado que escolhessem o que havia de comum, mesmo que, para isso, fosse necessário criar novas palavras-chave. Haveria ainda uma terceira divisa para a segunda etapa, portanto, tivemos algo ao redor de 20 minutos para esses momentos de explicação e reelaboração das palavras-chave.

Partimos, então, para a última atividade da segunda etapa, na qual cada um dos grupos teve como desafio e objetivo selecionar qual palavra-chave elaborada/selecionada coletivamente seria trazida para a partilha de todos os grupos. Não se tratava de elencar uma de cada cartão, como se estivesse criando um contraponto entre o negativo e o positivo, mas, de escolher uma só, fosse algo identificado como problema ou triunfo da profissão. Tendo já passado quase 50 minutos entre a fala inicial da direção, o prelúdio ao tema, a etapa I e as duas primeiras fases da etapa II, foi solicitado aos grupos que não investissem mais de 10 minutos nessa última divisa, pois seria fundamental concluir as três etapas dentro do período da ATPC.

Chegamos, então, na terceira e última etapa da atividade formativa, que foi pensada com o nome de "partilha", pois é o momento em que a tarefa individual e a coletiva são apresentadas para todos, com o propósito de aprender coletivamente. Os pequenos grupos foram desfeitos, retomando o semicírculo inicial. A primeira solicitação feita nessa etapa foi que partilhassem as palavras-chave, de modo que possíveis convergências pudessem ser identificadas de imediato, facilitando o diálogo posterior. As palavras-chaves enunciadas pelos participantes estão listadas no quadro 01 a seguir.

Quadro 1 - Palavras-chave a respeito dos elementos positivo/negativos do cotidiano docente

\begin{tabular}{|l|l|}
\hline Elementos negativos (cartão vermelho) & Elementos positivos (cartão verde) \\
\hline - indisciplina & - troca de saberes \\
- alunos descompromissados & - aprendizagem \\
- falta de respeito & - gostar do que faz \\
- desinteresse & - socialização \\
- alário baixo & - amigos \\
- conflitos de ideologia & - compromisso da equipe \\
- desatenção & - clima escolar \\
- alunos sem limites & - troca de experiências \\
- alunos sem sonhosicipação do alunado & \\
- problemas familiares & \\
\hline
\end{tabular}

Fonte: dados da experiência 
Tendo anotado as palavras-chave em confronto, ou seja, os elementos negativos dispostos lado a lado com os elementos positivos, começamos a compartilhar aquilo que havia sido divisado no final da segunda etapa, ou seja, buscamos elencar, no pequeno grupo, uma única palavra-chave escolhida como a mais substancial naquele momento. Essa partilha se tornaria ainda mais interessante, pois todos estavam divisando a constelação de possibilidades emergentes do cotidiano, sendo que cada um dos elementos arrolados poderia (e até mereceria) momentos de reflexão a respeito, individual e coletivo, exatamente como estávamos fazendo naquela ATPC. Isso foi capital para aquele objetivo anunciado de fazer ecoar a atividade para além dela mesma, ressoando posteriormente na prática cotidiana.

Dessa forma, pudemos partir para a partilha final, a qual foi conduzida a partir de três palavras-chave, sendo uma palavra oriunda de cada grupo, cientes de que a reflexão iniciada ali não seria resolvida naquele momento, tampouco estaria encerrada. Afinal, vários elementos da complexidade diária da profissão tinham sido pinçados ao longo da reflexão, trazidos a lume e, portanto, tornando-se pontos focais sobre os quais se podem elencar hipóteses de trabalho para tentar amenizar os problemas, bem como se podem tornar alento para eventuais momentos de desânimo com a docência.

Assim, as palavras-chave de cada grupo foram mencionadas, tendo um grupo desabafado a respeito de seus alunos "sem sonhos" e os outros dois grupos comentado sobre os aspectos mais positivos do trabalho, sendo o "compromisso da equipe" e o "clima escolar" provavelmente inspirados pela atmosfera do trabalho coletivo realizado pelo próprio grupo; claro que não nessa ATPC específica (pois um encontro não tem potência suficiente para criar senso de equipe), mas construído ao longo dos anos em que se encontram semanalmente para pensar sobre a docência.

Assim, tendo chegado à terceira etapa da atividade, que era o momento da partilha, pudemos encerrar nossa atividade proposta. $\mathrm{O}$ grupo de professores compreendeu que não iriamos pormenorizar o sentido de cada palavra-chave enunciada na última etapa, tampouco esquadrinhar os acontecimentos que a fizeram emergir no momento inicial de reflexão individual, ou porque teria sido a palavra escolhida na etapa de construção coletiva. Afinal, o propósito de tudo isso seria o de permanecer pensando a respeito, de forma comunitária e colaborativa, de preferência, pois somente a constante reflexão é que pode promover a transformação. Não um único momento, embora esse possa prover a necessária força de arranque para que se perceba que ser professor é estar permanentemente pensando a respeito de ser professor. 


\section{Considerações finais, ou a experiência vista por uma lente teórica}

A cultura, os significados partilhados e o meio social permeiam as experiências individuais, construindo as referências com as quais ou em contraposição às quais as pessoas agem. O conhecimento é enraizado na vida social, expressando e estruturando a identidade e as condições sociais dos que dele partilham. Por isso, ações sociais ou educacionais que têm por objetivo criar condições de mudanças conceituais, de atitudes e práticas precisam estar engrenadas com o meio sociocultural no qual as pessoas, os profissionais, que serão abrangidos por essas ações, vivem (GATTI, 2003, p. 196).

Nesse artigo, aproveitamos o ensejo de uma atividade formativa realizada em uma escola estadual para explorar o sentido da formação continuada em serviço. Balizada pela ideia de formação em contexto, buscou-se situar a atividade, desenvolvida durante uma ATPC, dentro de uma perspectiva muito maior, considerando a escola, seu alunado e corpo docente. Para planejar essa atividade, foi preciso considerar diversos aspectos do cotidiano, mas, também históricos da docência nessa escola. Além disso, a proposta era justamente conhecer parcialmente a realidade vivida, incluindo tanto seus incômodos presentes quantos suas virtudes conquistadas ao longo dos anos de trabalho da gestão e dos próprios professores.

Parece haver forte concordância a respeito da formação em contexto como sendo algo fundamental para a promoção da constante reflexão a respeito das contingências do trabalho docente. Tudo isso para alertar a respeito da complexidade e da fluidez do cotidiano, aspectos intrínsecos à própria vida cultural, que tendem a modificar com frequência o que se espera, se exige e se necessita da educação escolar. Pimenta (1994, p. 44) já havia expressado que "na formação de qualquer professor é preciso tomar-se o campo de atuação como referência. Isto é, tomá-lo como uma totalidade em todas as suas determinações, evidenciando as contradições nele presentes". Ferreira (2000, p. 75) anotou que "uma perspectiva de formação em contexto reclama de todos um papel ativo de construtores de saber [...] Assim os professores são considerados sujeitos e não objetos da formação". O que foi reforçado por Gatti (2003, p. 203), ao anotar que "é necessário que os programas que visam a inovações educacionais, aperfeiçoamentos, atualizações tenham um entrelaçamento concreto com a ambiência psicossocial em que esses profissionais trabalham e vivem".

Assim como bem anotou Imbernón (2010), as últimas três décadas foram marcadas por avanços teóricos a respeito da formação continuada em serviço, compreendendo cada veze mais o que implica a formação "em contexto". Não obstante, o autor reiteradamente reforça que esse avanço parece ter sido no papel, permanecendo ainda um tanto distante dos locais onde a educação acontece cotidianamente. 
Não há a menor pretensão de afirmar que uma única atividade, desenvolvida ao longo de uma única ATPC é a solução para que o progresso teórico da formação em contexto tornese realidade nas escolas. Uma única atividade, desenvolvida em uma única ATPC é justamente isso: uma atividade. Mas, se não é possível enaltecê-la como a resposta para o descompasso entre teoria e prática na formação docente, tampouco deve se desconsiderá-la como um caminho possível. Afinal, a experiência aqui descrita e analisada foi planejada em contexto e com o objetivo de ir além dela mesma, ajudando na percepção mais complexa a respeito do cotidiano multifacetado, cheio de intempéries, dilemas e problemas, mas também impregnado de aspectos positivos, de oportunidades e possibilidades.

O que foi proposto, e vivenciado, foi uma forma de olhar criticamente para o dia-a-dia, buscando sempre evidenciar o que se vive, para que se possa colocar as experiências rotineiras em perspectivas e analisá-las por vários e diferentes pontos de vista. Claro que é preciso colocar a singularidade da ação como um possível déficit para a formação continuada, afinal, o trabalho deve ser contínuo. Ainda assim, é possível qualificar a experiência aqui apresentada como positiva, pois nela continha o contexto, a intenção e a possibilidade de continuidade de se buscar novos saberes a partir do próprio lugar educativo em que se atua. Assim, espera-se que o sentido de uma atividade seja sempre relativizado, principalmente se o que se propõe é levar algo pronto, tecido na forma "como se deve ser docente", ou se a proposta é atuar em contexto, instigando a reflexão constante.

\section{REFERÊNCIAS}

FERREIRA, F. I. A formação e os seus efeitos: do modelo escolar à formação em contexto. In: FORMOSINHO, J. O. (org.). Associação criança: um contexto de formação em contexto. Braga: Livraria Minho, 2000. p. 63-79.

FORTUNATO, I. O relato de experiência como método de pesquisa educacional. In: FORTUnATO, I.; SHIGUNOV NETO, A. (org.). Método(s) de Pesquisa em Educação. São Paulo: Edições Hipótese, 2018. p. 37-50.

FORTUNATO, I. Um curso de formação continuada de professores como lócus de pesquisaação: relato de experiência. Estreiadiálogos, Braga, v. 3, n. 1, p. 90-105, 2018 b.

HARPER, B; CECCON, C.; OLIVEIRA, M. D.; OLIVEIRA, R. D. Cuidado, escola!: desigualdade, domesticação e algumas saídas. 24. ed. São Paulo: Editora Brasiliense, 1987.

IMBERNÓN, F. Formação continuada de professores. Porto Alegre: Artmed, 2010. 
INFORSATO, E. C.; PASSALACQUA, F. G. M. Formação continuada no espaço escolar: uma análise das dissertações e teses defendidas no estado de São Paulo. Revista Eletrônica da Educação, Jaú, v. 1, n. 1, p. 36-52, 2018.

MENEZES, C. M. A. Educação continuada de educadores: superando ambigüidades conceituais. Revista da FAEEBA - Educação e Contemporaneidade, Salvador, v. 12, n. 20, p. 311-320, jul./dez. 2003.

PIMENTA, S. G. Aspectos gerais da formação de professores para educação infantil nos programas de magistério $-2^{\circ}$ grau. In: BRASIL. Por uma política de formação do profissional de educação infantil. Brasília: Ministério da Educação e Cultura, 1994. p. 4350 .

ROSA, M. I. F. P. S.; SCHNETZLER, R. P. A investigação-ação na formação continuada de professores de ciências. Ciência \& Educação, Bauru, v. 9, n. 1, p. 27-39, 2003.

\section{Como referenciar este artigo}

FORTUNATO, I. O cotidiano escolar e a formação continuada docente em contexto: relato de experiência. Revista on line de Política e Gestão Educacional, Araraquara, v. 24, n. 3, p. 1666-1678, $\quad$ set./dez. 2020.2 e-ISSN:1519-9029. https://doi.org/10.22633/rpge.v24i3.14094

Submetido em: $20 / 05 / 2020$

Aprovado em: 25/08/2020

Publicado em: 01/09/2020 